\title{
The association between homocysteine levels and cardiovascular disease risk among middle-aged and elderly adults in Taiwan
}

\author{
Chin-Chuan Shih ${ }^{1}$, Yu-Lin Shih ${ }^{2}$ and Jau-Yuan Chen ${ }^{2,3^{*}}$ (D)
}

\begin{abstract}
Background: Our study aimed to determine the association between homocysteine levels and cardiovascular disease (CVD) risk in middle-aged and elderly adults in a community in northern Taiwan.

Methods: Participants in our study included adults aged 50 to 85 years old during community health examinations in 2019. A total of 396 people were enrolled, the ethnicity of all participants is Chinese. We divided participants according to tertiles of In[homocysteine] level (low, middle and high groups). The CVD risk was calculated by the Framingham cardiovascular risk score (FRS). An FRS $\geq 20 \%$ indicated high CVD risk. Pearson correlation coefficients were calculated between homocysteine level and other cardio-metabolic risk factors while adjusting for age. Multivariate logistic regression analysis was used to determine the association of high and middle In[homocysteine] groups with high CVD risk after adjusting age, sex, uric acid, creatinine, and body mass index (BMI). The Youden index and receiver operating characteristic (ROC) curves were performed to determine the optimized cut-off value.

Results: There were 396 people enrolled for analysis; $41.4 \%$ of participants were male, and the average age was $64.79( \pm 8.76)$. In our study, we showed a positive correlation of homocysteine with FRS. In the logistic regression models, higher In[homocysteine] levels was associated with higher CVD risk with a odds ratio (OR) of 2.499 and $95 \%$ confidence interval (CI) of 1.214 to 5.142 in the high homocysteine level group compared with the low homocysteine group after adjusting for traditional CVD risk factors. The area under the ROC curve was 0.667, and a In[homocysteine] cut-off value of $2.495 \mu \mathrm{mol} / \mathrm{L}$ was determined.
\end{abstract}

Conclusions: Middle-aged and elderly people with increased homocysteine levels were associated with higher FRSs in this Taiwan community. Furthermore, homocysteine was an independent risk factor for high CVD risk in this study.

Keywords: Homocysteine, Cardiovascular disease, Middle-aged and elderly, Framingham risk score

*Correspondence: welins@cgmh.org.tw

2 Department of Family Medicine, Chang-Gung Memorial Hospital, Linkou Branch, No.5, Fuxing St., Guishan Dist, Taoyuan City 333, Taiwan (R.O.C.)

Full list of author information is available at the end of the article

\section{Background}

Despite progress in medicine, the National Center for Health Statistics revealed that heart disease is still the leading cause of death in the United States [1]. The World Health Organization has also indicated that cardiovascular diseases (CVDs) are the number one cause of death globally [2], causing great loss and heavy burden in society [3]. Several CVD risk prediction models have been 
developed, and the Framingham Heart Study has been the most famous system for developing these prediction models [4]. Health care providers are always interested in finding reliable biomarkers for CVD.

Endothelial damage and inflammation initiate the series of steps in CVD development [5], and many biomarkers related to those steps have been investigated. C-reactive protein (CRP) has emerged as a potential useful marker for CVD, and chronic vessel inflammation suggests the possibility that subclinical states can be identified by an increasing CRP level as an indicator of circulating markers of inflammation before acute events occur [6]. The erythrocyte sedimentation rate (ESR) is another potentially novel biomarker to predict CVD, and a study showed that the ESR was mostly prolonged in patients with coronary heart disease [7].

Homocysteine is a nonproteinogenic $\alpha$-amino acid in the human body and cannot be obtained from the diet. Instead, homocysteine is synthesized from methionine via multiple biochemical steps. Homocysteine can be transformed into L-cysteine or back into L-methionine. Bacteria and plants have different pathways to produce homocysteine.

An elevated homocysteine level was considered to be a risk factor for CVD in recent studies [8]. It has been believed that homocysteine disrupts endothelial function, leading to vessel damage and, ultimately, to CVD [9, 10].

Previous studies focused on mechanisms and relationships, but in our study, we wanted to know whether homocysteine is an independent risk factor for CVD. We collected many parameters related to CVD, including the traditional cardio-metabolic risk factors, in this study. After analysis, our findings revealed that homocysteine was an independent risk factor for high CVD risk.

\section{Methods}

\section{Study design and participants}

This was a cross-sectional and community-based study with participants from a community health survey project conducted in 2019 in northern Taiwan. The inclusion criteria were as follows: (1) aged 50 years and below 85 years; (2) ability to complete a questionnaire; (3) living in the community and ability to walk to the clinic; (4) completion of all examinations. The exclusion criteria were (1) a history of heart disease or (2) missing or incomplete data (Fig. 1). Finally, 396 subjects were enrolled in this study and eligible for analysis. Each participant completed a questionnaire including personal information and medical history during face-to-face interviews. This study was approved by the Institutional Review Board (IRB) of Linkou Chang Gung Memorial Hospital, and all participants were informed and gave their consent before enrollment. All the participants signed consent form before entering the study.

\section{Data collection and measurements}

The content of the questionnaire included sex, age, alcohol drinking status (no drinking, occasional drinking, drinking $\geq 3$ days/week, or former drinker) and current smoking (self-reported current smoker, former smoker or nonsmoker). The health survey collected vegetarian diet, hypertension (HTN), diabetes mellitus (DM), and dyslipidemia data. Resting systolic and diastolic blood pressure (BP, $\mathrm{mmHg}$ ) were measured at least two times at rest. The following biochemical laboratory parameters were analyzed at the Roche ${ }^{\circledR}$ model lab at Taiwan E\&Q Clinical Laboratory: fasting plasma glucose (FPG), homocysteine, low-density lipoprotein (LDL-C, mg/dl), high-density lipoprotein (HDL-C, mg/dl), total cholesterol (TC, mg/dl), triglyceride level (TG, $\mathrm{mg} / \mathrm{dl}$ ), alanine transaminase (ALT, $\mathrm{mg} / \mathrm{dl})$, creatinine $(\mathrm{mg} / \mathrm{dl})$, and uric acid $(\mathrm{mg} / \mathrm{dl})$. Waist circumference $(\mathrm{WC}, \mathrm{cm})$ was measured at the midpoint between the inferior margin of the last rib and the iliac crest in a horizontal plane while the individual was in an upright position. Body mass index (BMI) was calculated as the person's weight in kilograms divided by the square of height in meters.

\section{Definition of CVD risk and other variables}

In this study, the CVD risk was defined according to the 2008 general CVD risk model from the Framingham Heart Study, which included age, sex, systolic blood pressure (SBP), anti-HTN medication, current smoking, DM, TC, and HDL-C [13]. According to the previous study, the participants can be categorized into low-risk group (Framingham Risk Score $[\mathrm{FRS}]<10 \%$ ), a middle-risk group $(10 \% \leq \mathrm{FRS}<20 \%)$, and a high-risk group (FRS $\geq 20 \%$ ) [11], so we classified our participants into two categories: high CVD risk (FRS $\geq 20 \%$ ) and non-high CVD risk (FRS $<20 \%$ ) for logistic regression. DM was defined as an FPG $\geq 126 \mathrm{mg} / \mathrm{dL}$ or the use of oral hypoglycemic agents or insulin therapy. HTN was defined as $\mathrm{SBP} \geq 140 \mathrm{mmHg}$, diastolic blood pressure $(D B P) \geq 90 \mathrm{mmHg}$, or the use of treatment for HTN. Dyslipidemia was defined as LDL-C $\geq 130 \mathrm{mg} / \mathrm{dL}$, $\mathrm{HDL}-\mathrm{C}<40 \mathrm{mg} / \mathrm{dL}$ in males $\mathrm{or}<50 \mathrm{mg} / \mathrm{dL}$ in females, $\mathrm{TG} \geq 150 \mathrm{mg} / \mathrm{dL}, \mathrm{TC} \geq 200 \mathrm{mg} / \mathrm{dL}$, or the use of lipidlowering medication.

\section{Statistical analysis}

In order to normalize our data, we used Ln-transformation for homocysteine level and FRS. Participants were divided into three groups according to $\ln$ [homocysteine] level: low $\ln$ [homocysteine] level $(<2.42)$, middle $\ln [$ homocysteine] level $(2.42-2.66)$, and 


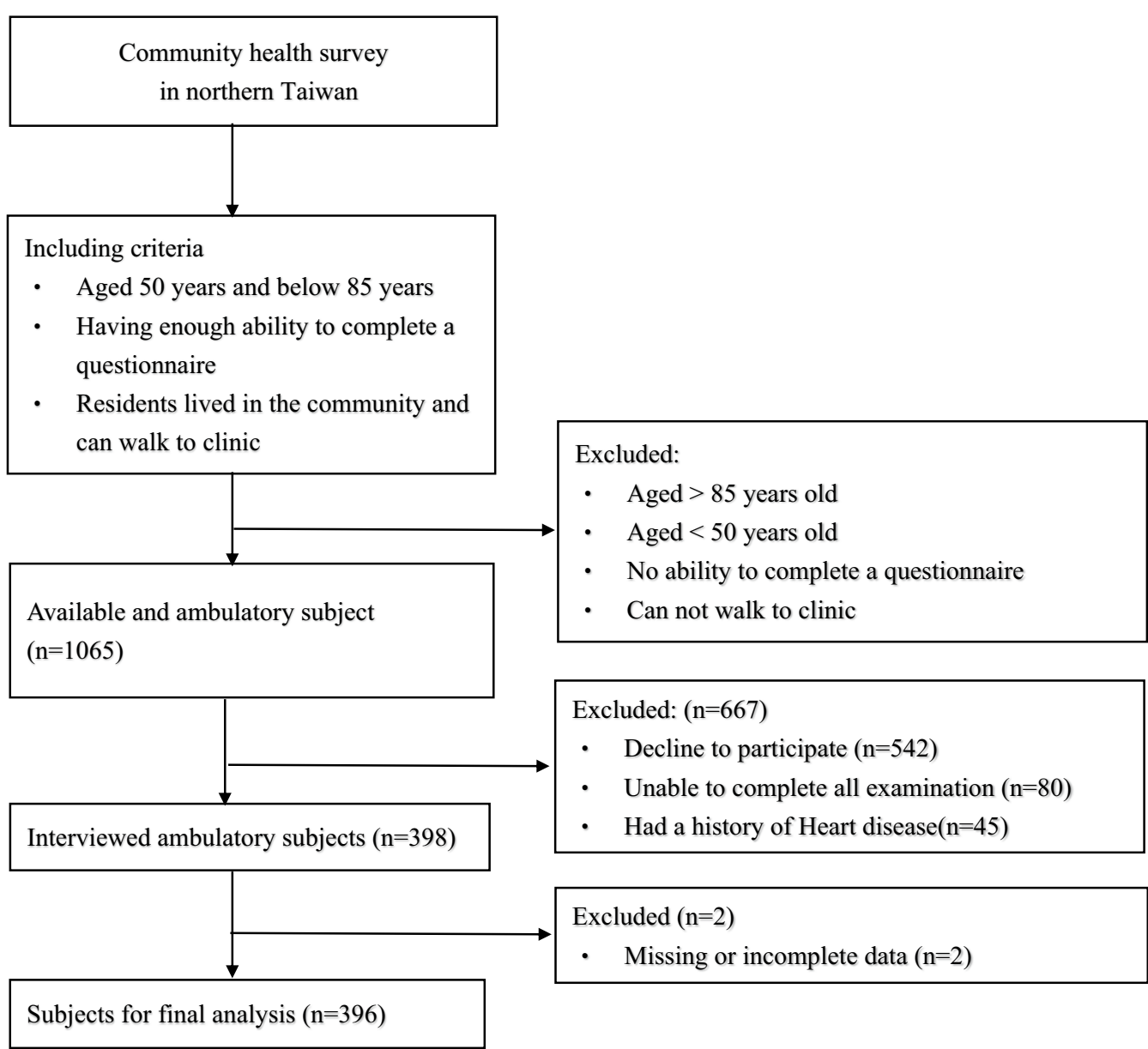

Fig. 1 Flow chart of study subjects

high $\ln$ [homocysteine] level ( $\geq 2.67$ ). For laboratory and clinical data within each group, continuous variables were expressed as the mean $\pm S D$ and analyzed by oneway Analysis of variance (ANOVA); categorical variables were expressed as $\mathrm{n}(\%)$ and analyzed by chi-square test. Pearson's correlation coefficient was used to analyze correlations between $\ln$ [homocysteine] and age, $\ln$ [FRS], FPG, TG, HDL-C, LDL-C, uric acid, WC, SBP, DBP and BMI; the Pearson's correlation adjusted by age was also presented. The Pearson's correlation indicated the potential risk factors for us to discuss in more detail in logistic regression analysis. In addition, we further calculated the prevalence of high CVD risk according to the three levels of homocysteine. Finally, each three groups which were determined by the level of the $\ln$ [homocysteine] were divided into two sub-groups: high CVD risk subgroup (FRS $\geq 20 \%$ ) and non-high CVD risk subgroup $($ FRS $<20 \%)$, then a multiple logistic regression was performed to evaluate the association between homocysteine and high CVD risk, for the purpose of binary logistic regression analysis we had mentioned that two groups of outcome variable would be more appropriate. In our study, a $p$ value of $<0.05$ was considered statistically significant. Youden index, the sum of sensitivity and specificity minus one, was performed. The maximum result of the Youden index decided the optimized $\ln$ [homocysteine] cut-off value to determine high CVD risk. We also presented receiver operating characteristic (ROC) curves. All statistical analyses were performed using SPSS for Windows (IBM Corp. Released 2011. IBM SPSS Statistics, version 25.0. Armonk, NY: IBM Corp.).

\section{Results}

Data from middle-aged and elderly people from communities in northern Taiwan were analyzed in this study. A total of 396 individuals, including 164 men (41.4\%) and 232 women (58.6\%) with a mean age of $63.72 \pm 8.76$ years, were enrolled for analysis. Table 1 summarizes the demographic and clinical characteristics of the study subjects. The enrolled patients were 
Table 1 General characteristics of the study population according to tertiles of In[homocysteine]

\begin{tabular}{|c|c|c|c|c|c|}
\hline \multirow[t]{4}{*}{ Variable } & \multicolumn{5}{|l|}{ In[homocysteine] } \\
\hline & \multirow{3}{*}{$\begin{array}{l}\text { Total } \\
(n=396)\end{array}$} & \multirow{3}{*}{$\begin{array}{l}\text { Low } \\
(<2.42) \\
(n=132)\end{array}$} & \multirow{3}{*}{$\begin{array}{l}\text { Middle } \\
(2.42-2.66) \\
(n=130)\end{array}$} & \multirow{3}{*}{$\begin{array}{l}\text { High } \\
(\geq 2.67) \\
(n=134)\end{array}$} & \multirow[t]{3}{*}{$p$ value for trend } \\
\hline & & & & & \\
\hline & & & & & \\
\hline Age (year) & $64.79 \pm 8.76$ & $64.17 \pm 8.5$ & $65.32 \pm 9.34$ & $64.87 \pm 8.47$ & 0.521 \\
\hline Gender (male), n(\%) & $164(41.4)$ & $24(18.2)$ & $52(40.0)$ & $88(65.7)$ & $<0.001$ \\
\hline Fasting plasma glucose (mg/dL) & $109.79 \pm 35.65$ & $102.89 \pm 20.65$ & $111.74 \pm 41.87$ & $114.68 \pm 39.74$ & 0.007 \\
\hline FRS (\%) & $2.61 \pm 0.67$ & $2.35 \pm 0.62$ & $2.60 \pm 0.69$ & $2.87 \pm 0.60$ & $<0.001$ \\
\hline In[homocysteine(umol/L)] & $2.56 \pm 0.32$ & $2.23 \pm 0.15$ & $2.54 \pm 0.07$ & $2.90 \pm 0.22$ & $<0.001$ \\
\hline $\mathrm{TG}(\mathrm{mg} / \mathrm{dL})$ & $141.07 \pm 110.00$ & $137.95 \pm 105.33$ & $141.65 \pm 130.97$ & $143.59 \pm 91.41$ & 0.677 \\
\hline LDL-C (mg/dl) & $109.69 \pm 33.99$ & $113.27 \pm 32.46$ & $108.09 \pm 35.97$ & $107.71 \pm 33.46$ & 0.183 \\
\hline $\mathrm{HDL}-\mathrm{C}(\mathrm{mg} / \mathrm{dl})$ & $53.56 \pm 14.51$ & $56.99 \pm 13.87$ & $54.42 \pm 14.30$ & $49.34 \pm 14.41$ & $<0.001$ \\
\hline Uric Acid (mg/dL) & $5.63 \pm 1.52$ & $5.13 \pm 1.27$ & $5.53 \pm 1.35$ & $6.23 \pm 1.70$ & $<0.001$ \\
\hline $\operatorname{ALT}(U / L)$ & $27.16 \pm 22.82$ & $26.06 \pm 25.70$ & $28.15 \pm 21.44$ & $27.28 \pm 21.18$ & 0.665 \\
\hline Creatinine (mg/dl) & $0.87 \pm 0.43$ & $0.73 \pm 0.14$ & $0.80 \pm 0.19$ & $1.07 \pm 0.66$ & $<0.001$ \\
\hline waist circumference (cm) & $85.36 \pm 10.83$ & $81.01 \pm 10.06$ & $86.01 \pm 10.55$ & $89.00 \pm 10.40$ & $<0.001$ \\
\hline $\mathrm{SBP}(\mathrm{mmHg})$ & $137.30 \pm 17.49$ & $134.28 \pm 16.60$ & $137.29 \pm 18.17$ & $140.29 \pm 17.29$ & 0.005 \\
\hline $\mathrm{DBP}(\mathrm{mmHg})$ & $85.19 \pm 10.98$ & $83.61 \pm 10.62$ & $84.04 \pm 10.35$ & $87.86 \pm 11.49$ & 0.001 \\
\hline BMI $\left(\mathrm{kg} / \mathrm{m}^{2}\right)$ & $25.59 \pm 3.84$ & $24.53 \pm 3.38$ & $25.49 \pm 3.54$ & $26.74 \pm 4.23$ & $<0.001$ \\
\hline Smoking, n(\%) & $50(12.6)$ & $7(5.3)$ & $14(10.8)$ & $29(21.6)$ & $<0.001$ \\
\hline Alcohol drinking, n(\%) & $28(7.1)$ & $8(6.1)$ & $9(6.9)$ & $11(8.2)$ & 0.495 \\
\hline HTN, n(\%) & 201(50.8) & $55(41.7)$ & $63(48.5)$ & 83(61.9) & 0.001 \\
\hline $\mathrm{DM}, \mathrm{n}(\%)$ & 133(33.6) & $29(22.0)$ & $49(37.7)$ & $55(41.0)$ & 0.001 \\
\hline Hyperlipidemia, n(\%) & 153(38.6) & 49(37.1) & $43(33.1)$ & $61(45.5)$ & 0.158 \\
\hline Vegetarian, n(\%) & $12(3.0)$ & $4(3.0)$ & $3(2.3)$ & $5(3.7)$ & 0.737 \\
\hline
\end{tabular}

Clinical characteristics are expressed as mean \pm SD for continuous variables and $n(\%)$ for categorical variables. $p$ value were derived from one-way analysis of variance (one-way ANOVA) for continuous variables and chi-square test for categorical variables

FRS, Framingham cardiovascular risk score; TG, triglyceride; LDL-C, low-density lipoprotein cholesterol; HDL-C, high-density lipoprotein cholesterol; ALT, alanine aminotransferase; SBP, systolic blood pressure; DBP, diastolic blood pressure; BMI, body mass index; HTN, hypertension; DM, diabetes mellitus; CVD, cardiovascular disease

categorized into three subgroups according to their $\ln$ [homocysteine] level group: low $\ln$ [homocysteine] level $(<2.42)$, middle $\ln$ [homocysteine] level (2.42-2.66), and high $\ln$ [homocysteine] level $(\geq 2.66$ ). There were no statistically significant differences in age, TG concentration, LDL-C concentration, ALT concentration, alcohol drinking, prevalence of hyperlipidemia, or vegetarian diet between the low, middle and high $\ln$ [homocysteine] level groups. The participants in the high $\ln$ [homocysteine] group were more likely to be male and have a higher FPG level, $\ln [\mathrm{FRS}]$, uric acid concentration, creatinine concentration, waist circumference, SBP, DBP, BMI, smoking rate, prevalence of $\mathrm{HTN}$, and prevalence of DM than those in the low $\ln$ [homocysteine] group. In addition, HDL-C was lower among participants in the high $\ln [$ homocysteine] group.

Table 2 demonstrates the correlations between $\ln$ [homocysteine] level and various cardiovascular risk factors. $\ln$ [homocysteine] level was positively correlated with $\ln [\mathrm{FRS}]$, FPG, uric acid concentration, waist circumference, SBP, DBP, and BMI; $\ln$ [homocysteine] level was negatively correlated with HDL-C concentration. Most of these associations remained statistically significant after adjusting for age. Age, TG and LDL-C concentration were not significantly associated with $\ln$ [homocysteine]. Figure 2 shows a scatterplot of CVD risk by $\ln$ [homocysteine] level. The Pearson's correlation was 0.368 with a $p$ value $<0.001$.

In Table 3, Participants were divided into three groups according to $\ln [$ homocysteine] level: low $\ln$ [homocysteine] level $(<2.42)$, middle $\ln$ [homocysteine] level (2.42-2.66), and high $\ln$ [homocysteine] level $(\geq 2.66)$. Than each groups were further divided into two sub-groups: high CVD risk $(F R S \geq 20$ ) and nonhigh $C V D$ risk $(F R S<20)$. Multiple logistic regression models were used to calculate the odds ratio (OR) of $\ln$ [homocysteine] levels with high CVD risk after adjustment for other risk factors in each model. The high and 
Table 2 The Pearson correlation between In[homocysteine] and cardio-metabolic risk factors

\begin{tabular}{|c|c|c|c|c|}
\hline \multirow[t]{3}{*}{ Variable } & \multicolumn{4}{|c|}{ In[homocysteine] } \\
\hline & \multicolumn{2}{|l|}{ Unadjusted } & \multicolumn{2}{|c|}{ Adjusted for age } \\
\hline & Correlation & $p$ value & Correlation & $p$ value \\
\hline Age (year) & 0.092 & 0.068 & B N/A & N/A \\
\hline $\ln [$ FRS (\%)] & 0.368 & $<0.001$ & 0.391 & $<0.001$ \\
\hline $\begin{array}{l}\text { Fasting plasma glucose } \\
\text { (mg/dL) }\end{array}$ & 0.103 & 0.040 & 0.094 & 0.063 \\
\hline $\mathrm{TG}(\mathrm{mg} / \mathrm{dL})$ & 0.025 & 0.618 & 30.408 & 0.521 \\
\hline $\mathrm{HDL}-\mathrm{C}(\mathrm{mg} / \mathrm{dl})$ & -0.216 & $<0.001$ & $1-0.495$ & $<0.001$ \\
\hline LDL-C (mg/dl) & -0.082 & 0.103 & $3-0.047$ & 0.348 \\
\hline Uric Acid (mg/dL) & 0.351 & $<0.001$ & 0.299 & $<0.001$ \\
\hline waist circumference (cm) & 0.287 & $<0.001$ & 0.397 & $<0.001$ \\
\hline $\mathrm{SBP}(\mathrm{mmHg})$ & 0.152 & 0.002 & 20.555 & $<0.001$ \\
\hline $\mathrm{DBP}(\mathrm{mmHg})$ & 0.165 & 0.001 & 0.484 & $<0.001$ \\
\hline BMI $\left(\mathrm{kg} / \mathrm{m}^{2}\right)$ & 0.214 & $<0.001$ & 0.325 & $<0.001$ \\
\hline
\end{tabular}

FRS, Framingham cardiovascular risk score; TG, triglyceride; LDL-C, low-density lipoprotein cholesterol; HDL-C, high-density lipoprotein cholesterol; SBP, systolic blood pressure; DBP, diastolic blood pressure; BMI, body mass index

middle $\ln$ [homocysteine] groups were compared with the low $\ln [$ homocysteine] group in all three models. Model 1 was unadjusted; Model 2 was adjusted for age and sex; Model 3 was adjusted for age, sex, uric acid, creatinine and BMI. $\ln$ [homocysteine] levels remained statistically significant even after adjusting in Table 3. The OR for high CVD risk was 2.499 (1.214 to 5.142) in the high $\ln$ [homocysteine] group compared with the low $\ln$ [homocysteine] group in model 3. In Fig. 3, the participants in the high $\ln$ [homocysteine] group had higher prevalence of high CVD risk. Figure 4 shows the ROC curve for homocysteine level as a biomarker of high CVD risk. Youden index were used to determine the optimized homocysteine cut-off value to determine high CVD risk. The area under the ROC curve was 0.67; the $\ln$ [homocysteine] cut-off value of 2.495 with a sensitivity of 0.75 and a specificity of 0.49 (Table 4), and the Youden index was 0.24 .

\section{Discussion}

CVD has been a worldwide healthcare burden for a long time, and medical providers are always interested in finding reliable biomarkers for CVD and CVD risk factors. In this community-based study, we investigated homocysteine levels in association with high CVD risk in middleaged and elderly people in northern Taiwan. Looking at three $\ln$ [homocysteine] tertiles (Table 1), there was a rising proportion of males, HTN, smoking status, and SBP as the $\ln$ [homocysteine] level increased. These results correspond with previous studies, [12-14] but HDL had an inverse relationship with $\ln$ [homocysteine], which was also noted in a previous study [15]. According to the Framingham risk score, male sex, HTN, smoking

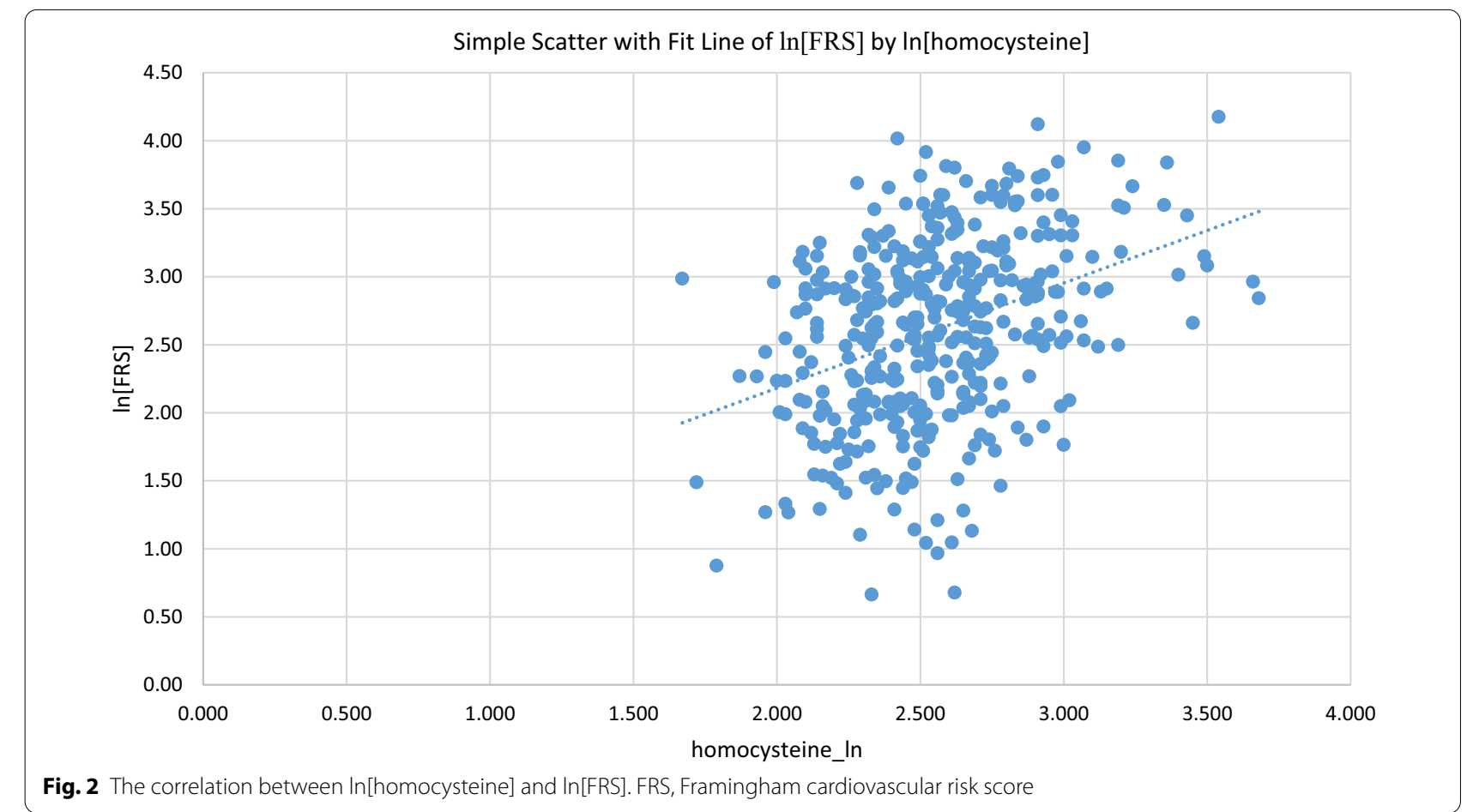


Table 3 association between In[homocysteine] and high cardiovascular risk

\begin{tabular}{|c|c|c|c|c|c|c|c|c|c|}
\hline \multirow[t]{2}{*}{ Variable } & \multicolumn{3}{|c|}{ Model 1} & \multicolumn{3}{|c|}{ Model 2} & \multicolumn{3}{|c|}{ Model 3} \\
\hline & OR & (95\% C.I.) & $p$ value & OR & (95\% C.I.) & $p$ value & OR & (95\% C.I.) & $p$ value \\
\hline Low & 1 & - & - & 1 & - & - & 1 & - & - \\
\hline Middle & 2.366 & 1.276 to 4.388 & 0.006 & 2.073 & 1.070 to 4.013 & 0.031 & 1.865 & 0.955 to 3.641 & 0.068 \\
\hline High & 3.772 & 2.075 to 6.854 & $<0.001$ & 3.348 & 1.709 to 6.559 & $<0.001$ & 2.499 & 1.214 to 5.142 & 0.013 \\
\hline
\end{tabular}

Model 1: unadjusted

Model 2: unadjusted for model 1 plus age and gender

Model 3: adjusted for model 2 plus uric acid, creatinine, and BMI

BMI, body mass index
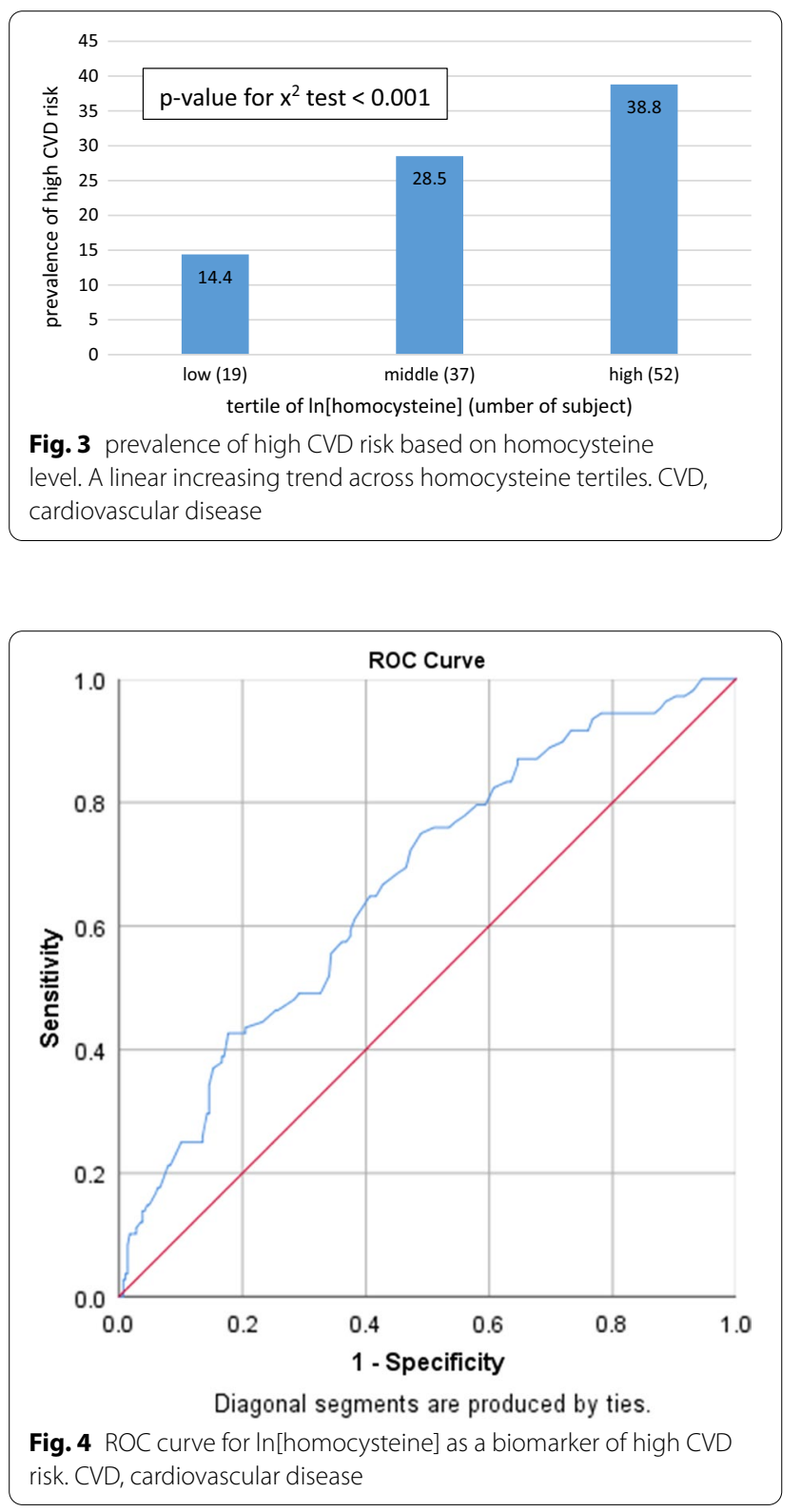

Table 4 The areas under ROC curve (AUC), sensitivity, specificity by the optimized cut-off points for In[homocysteine] as a biomarker of high cardiovascular risk

\begin{tabular}{llclll}
\hline Variable & Area & $p$ value & $\begin{array}{l}\text { Cut- } \\
\text { off } \\
\text { point }\end{array}$ \\
\hline In[homocysteine] & $\begin{array}{l}0.667(0.608- \\
0.726)\end{array}$ & $<0.000$ & 2.495 & 0.75 & 0.49 \\
\hline
\end{tabular}

status, and SBP are risk factors for CVD, but HDL serve as a protective factor against CVD. [16] Meanwhile, an increase in $\ln$ [homocysteine] level is directly associated with increases in $\ln$ [FRS]. In Fig. 3, the prevalence of high CVD risk was significantly greater in the higher tertiles of $\ln$ [homocysteine]. These findings led us to speculate that an association exists between homocysteine levels and FRS.

In Table 2, we found a positive correlation between $\ln$ [homocysteine] levels and $\ln [\mathrm{FRS}]$, along with other traditional CVD risk factors such as BMI and waist circumference. Most the correlations reached statistical significance even after adjustment for age. The Pearson's correlation between $\ln$ [homocysteine] and $\ln [$ FRS] was 0.391 with a $\mathrm{p}$ value $<0.001$, which corresponds with a previous study that homocysteine can be a risk factor for CVD [7, 17]. All the previous results raise the question of whether homocysteine can be an important risk factor for predicting high CVD risk. Hence, we wanted to know whether $\ln$ [homocysteine] can be an independent risk factor for high CVD risk or not. In the next step, we used logistic regression model to see how the homocysteine affects CVD risk.

In the logistic regression models (Table 3), the middle and high $\ln$ [homocysteine] groups were compared with the low $\ln$ [homocysteine] group, and the prevalence of high CVD risk increased as $\ln$ [homocysteine] increased. After adjusting for age, sex, uric acid, creatinine and BMI, the odds ratio (OR) and 95\% confidence 
interval for high CVD risk was 2.499 (1.214 to 5.142) in the high $\ln$ [homocysteine] group compared with the low $\ln$ [homocysteine] group. This result confirmed that $\ln$ [homocysteine] was an independent risk factor for high CVD risk.

Figure 4 shows the ROC curve for $\ln$ [homocysteine] as a biomarker for high CVD risk. The AUC was 0.667. In Table 4, Youden index were used to determine the optimized homocysteine cut-off value to determine high CVD risk. The Youden index was 0.24 and the optimized cut-off value for $\ln$ [homocysteine] was 2.495 with a sensitivity of 0.75 and a specificity of 0.49 . Although this result was not sensitive enough for screening test and was not specific enough for diagnostic test, the result still obviously indicated the positive relationship between $\ln$ [homocysteine] and high CVD risk.

There are many possible explanations for the relationship between homocysteine and CVD. Homocysteine is a sulfur-containing amino acid that is a metabolic precursor of methionine and cystathionine [18]. Elevated homocysteine levels are not only considered a risk factor for cardiovascular disease $[8,16,18]$ but are also linked to various diseases, such as chronic kidney disease [19]. A previous animal study with cell culture showed that high homocysteine levels had toxic effects on the vasculature, with manifestations of medial remodeling, adventitial inflammation, and endothelial injury. The mechanisms include abnormal protein metabolism [20] and the production of reactive oxidative species [21, 22]. Homocysteine specifically damages the endothelial, medial and adventitial layers of the vessel wall [9], than vessel damage leads to atherosclerosis [23], hypertension [24], stroke [25], coronary artery disease [26], peripheral arterial disease [27], and aneurysm [28].

Many studies have pointed out the positive relationship between homocysteine and CVD, but most of them did not consider the influence of other traditional CVD risk factors on the relationship between homocysteine and CVD. In our study, we considered traditional CVD risk factors and other parameters, and the results revealed that homocysteine level may be an important independent predictor of high CVD risk. Our findings may have an impact on health screening among middle-aged and elderly populations. In addition to those traditional parameters of CVD, homocysteine level should be considered an important biomarker in health screening, and people with elevated homocysteine should be warned of higher CVD risk.

However, our study still had limitations. We recruited participants from northern Taiwan as our favored population. The characteristics of those participants might differ from characteristics in the general population, the selection bias should be considered, so the findings cannot be generalized to the whole middle-aged and elderly population in Taiwan. The results of our study should not be extrapolated to other regions of Taiwan. Future studies using random sampling of communities with a wider range of regions would make the research more discursive.

\section{Conclusions}

This study showed that increased homocysteine levels are associated with high CVD risk among middle-aged and elderly populations in Taiwan. After this cross-sectional study examining the relationship between homocysteine and CVD risk, further follow-up and cohort studies are required to determine the effect of homocysteine on CVD.

\section{Abbreviations}

CVD: Cardiovascular disease; FRS: Framingham cardiovascular risk score; HTN: Hypertension; DM: Diabetes mellitus; BMI: Body mass index; ROC: Receiver operating characteristic; OR: Odds ratio; CVDs: Cardiovascular diseases; CRP: C-reactive protein; ESR: Erythrocyte sedimentation rate; IRB: Institutional Review Board; BP: Blood pressure; FPG: Fasting plasma glucose; LDL-C: Lowdensity lipoprotein; HDL-C: High-density lipoprotein; TC: Total cholesterol; TG: Triglyceride level; ALT: Alanine transaminase; WC: Waist circumference; BMI: Body mass index; DBP: Diastolic blood pressure; SBP: Systolic blood pressure; ANOVA: Analysis of variance; AUC: Areas under ROC curve.

\section{Acknowledgements \\ Not applicable}

\section{Authors' contributions}

FC analyzed and interpreted the patient data regarding the hematological disease and the transplant. RH performed the histological examination of the kidney, and was a major contributor in writing the manuscript. All authors read and approved the final manuscript.

\section{Funding}

This study was supported by United Safety Medical Group (USGN2019001).

\section{Availability of data and materials}

The datasets used and/or analysed during the current study are available from the corresponding author on reasonable request.

\section{Declarations}

\section{Ethics approval and consent to participate}

This study was approved by the Institutional Review Board (IRB) of Linkou Chang Gung Memorial Hospital (No.1901150007), all participants were informed and gave their consent before enrollment.

\section{Consent for publication}

Not applicable

\section{Competing interests}

The authors declare that they have no competing interests.

\section{Author details}

${ }^{1}$ General Administrative Department, United Safety Medical Group, 2F, No.302, Zhongzheng Rd., Xinzhuang District, New Taipei City 242, Taiwan (R.O.C.). ${ }^{2}$ Department of Family Medicine, Chang-Gung Memorial Hospital, Linkou Branch, No.5, Fuxing St., Guishan Dist, Taoyuan City 333, Taiwan (R.O.C.).

${ }^{3}$ Chang Gung University College of Medicine, Taoyuan, No.259, Wenhua 1st Rd., Guishan Dist, Taoyuan City 333, Taiwan (R.O.C.). 
Received: 5 November 2020 Accepted: 9 April 2021

Published online: 20 April 2021

\section{References}

1. Centers for Disease Control and Prevention. Leading causes of death and numbers of deaths, by sex, race, and Hispanic origin: United States, 1980 and 2014. CDC;2015.

2. World Health Organization. World Health Organization: deaths by cause, age and sex, by world bank income group, 2000-2015. WHO: Geneva 2018

3. Pagidipati NJ, Gaziano TA. Estimating deaths from cardiovascular disease: a review of global methodologies of mortality measurement. Circulation. 2013;2:12.

4. Mahmood SS, Levy D, Vasan RS, Wang TJ. The Framingham Heart Study and the epidemiology of cardiovascular disease: a historical perspective. Lancet. 2013:9:29.

5. Libby P. Inflammation and cardiovascular disease mechanisms. Am J Clin Nutrit. 2006:83(2):456S-460S

6. Nilsson J. CRP — marker or maker of cardiovascular disease. Arterioscler Thromb Vasc Biol. 2005:25:1527-8

7. Yayan J. Erythrocyte sedimentation rate as a marker for coronary heart disease. Vasc Health Risk Manag. 2012:8:219-23.

8. Chrysant SG, Chrysant GS. The current status of homocysteine as a risk factor for cardiovascular disease: a mini review. Exp Rev Cardiovasc Therapy. 2018;16(8):559-65.

9. Balint B, Jepchumba VK, Guéant JL, Guéant-Rodriguez RM. Mechanisms of homocysteine-induced damage to the endothelial, medial and adventitial layers of the arterial wall. Biochimie. 2020;173:100-6.

10. Finch $\mathrm{M}$, Joseph J. Homocysteine, cardiovascular inflammation, and myocardial remodeling. Cardiovasc Haematol Disorders Drug Targets. 2010;10(4):241-5.

11. nkle Brachial Index Collaboration. Ankle brachial index combined with framingham risk score to predict cardiovascular events and mortality: a meta-analysis. JAMA. 2008:300(2):197.

12. Lin $B Y, L i P, W u X D$, Li H, Zeng ZY. The relationship between homocysteine, blood pressure variability, and left ventricular hypertrophy in patients with essential hypertension: an observational study. Advances in therapy. 2020;37(1):381-9.

13. Awasthi M, Omoike OE, Paul TK, Ridner SL, Mamudu HM, An association between smoking status and homocysteine levels and whether this association is modified by sex hormones and cholesterol (2019)

14. Weng H, Li Y, Fan F, Yang H, Zhou G, Sun P, Li J. The association between total homocysteine and blood pressure in two independent Chinese populations. J Hum Hyperten. 2020;34(9):657-65.

15. Momin M, Jia J, Fan F, Li J, Dou J, Chen D, Zhang Y. Relationship between plasma homocysteine level and lipid profiles in a community-based Chinese population. Lip Health Disease. 2017;16(1):1-7.
16. Lloyd-Jones DM, Wilson PW, Larson MG, Beiser A, Leip EP, D'Agostino RB, Levy D. Framingham risk score and prediction of lifetime risk for coronary heart disease. Am J Cardiol. 2004:94(1):20-4.

17. Chrysant SG, Chrysant GS. The current status of homocysteine as a risk factor for cardiovascular disease: a mini review. Exp Rev Cardiovas Therapy. 2018;16(8):559-65

18. Castro R, Rivera I, Blom HJ, Jakobs C, De Almeida IT. Homocysteine metabolism, hyperhomocysteinaemia and vascular disease: an overview. I Inherited Metab Dis. 2006:29(1):3-20

19. Menon V, Sarnak MJ, Greene T, Wang X, Pereira AA, Beck GJ, Shlipak MG. Relationship between homocysteine and mortality in chronic kidney disease. Circulation. 2006;113(12):1572-7.

20. Obeid R. The metabolic burden of methyl donor deficiency with focus on the betaine homocysteine methyltransferase pathway. Nutrients. 2013;5(9):3481-95.

21. Bukharaeva E, Shakirzyanova A, Khuzakhmetova V, Sitdikova G, Giniatullin R. Homocysteine aggravates ROS-induced depression of transmitter release from motor nerve terminals: potential mechanism of peripheral impairment in motor neuron diseases associated with hyperhomocysteinemia. Front Cellular Neurosci. 2015;9:391.

22. Ke XD, Foucault-Bertaud A, Genovesio C, Dignat-George F, Lamy E, Charpiot P. Homocysteine modulates the proteolytic potential of human arterial smooth muscle cells through a reactive oxygen species dependant mechanism. Mol Cellular Biochem. 2010;335(1):203-10.

23. Durand P, Prost M, Loreau N, Lussier-Cacan S, Blache D. Impaired homocysteine metabolism and atherothrombotic disease. Lab Investig. 2001:81(5):645-72.

24. Sreckovic B, Sreckovic VD, Soldatovic I, Colak E, Sumarac-Dumanovic M, Janeski $\mathrm{H}$, Mrdovic I. Homocysteine is a marker for metabolic syndrome and atherosclerosis. Diabetes Metab Syndrome Clin Res Rev. 2017:11(3):179-82.

25. Lehotský J, Tothová B, Kovalská M, Dobrota D, Beňová A, Kalenská D, Kaplán P. Role of homocysteine in the ischemic stroke and development of ischemic tolerance. Front Neurosci. 2016;10:538.

26. Schaffer A, Verdoia M, Barbieri L, Aprami TM, Suryapranata H, Marino P, Luca GD. High-density lipoproteins and coronary artery disease: a singlecenter cohort study. Angiology. 2014;65(8):696-702.

27. Andras A, Stansby G, Hansrani M. Homocysteine lowering interventions for peripheral arterial disease and bypass grafts. Cochrane Database Syst Rev, 2013;7

28. Krishna SM, Dear A, Craig JM, Norman PE, Golledge J. The potential role of homocysteine mediated DNA methylation and associated epigenetic changes in abdominal aortic aneurysm formation. Atherosclerosis. 2013:228(2):295-305.

\section{Publisher's Note}

Springer Nature remains neutral with regard to jurisdictional claims in published maps and institutional affiliations.
Ready to submit your research? Choose BMC and benefit from:

- fast, convenient online submission

- thorough peer review by experienced researchers in your field

- rapid publication on acceptance

- support for research data, including large and complex data types

- gold Open Access which fosters wider collaboration and increased citations

- maximum visibility for your research: over 100M website views per year

At BMC, research is always in progress.

Learn more biomedcentral.com/submissions 